\title{
A TRADICIONAL ACEPÇÃO DO “ESTADO" ANALISADA A PARTIR DA CONJUGAÇÃO DOS DIREITOS AO MEIO AMBIENTE ECOLOGICAMENTE EQUILIBRADO E DA CULTURA NO ÂMBITO DOS CONHECIMENTOS TRADICIONAIS ASSOCIADOS À BIODIVERSIDADE
}

\author{
Nathalie Kuczura Nedel ${ }^{*}$ \\ Isabel Christine De Gregori**
}

\begin{abstract}
RESUMO: O Estado possui a soberania, o território e o povo como sendo os elementos presentes na sua tradicional concepção. Ocorre que desde o seu surgimento emergiram novas situações, dentre as quais se alocam os conhecimentos tradicionais associados à biodiversidade. Diante disso, cabe questionar, em que medida pode-se, ainda, tratar da instituição Estado, na sua configuração tradicional, frente à conjugação dos direitos à cultura e ao meio ambiente ecologicamente equilibrado no âmbito dos conhecimentos tradicionais? Para responder ao problema de pesquisa posto, utilizaram-se, respectivamente, como método de abordagem e de procedimento o dedutivo, bem como o procedimento o estruturalista.
\end{abstract}

Palavras-chave: Conhecimentos tradicionais associados à biodiversidade; Estado; Povo; Soberania; Território.

THE TRADITIONAL ACCEPTANCE OF THE "STATE" ANALYZED FROM THE CONJUGATION OF RIGHTS TO THE ENVIRONMENT ECOLOGICALLY BALANCED AND CULTURE IN THE FRAMEWORK OF TRADITIONAL KNOWLEDGE ASSOCIATED WITH BIODIVERSITY

\begin{abstract}
The State has sovereignty, territory and people as the elements present in the traditional conception. From the outset, new situations emerged, among which the traditional knowledge associated with biodiversity was allocated. In view of this, it is necessary to question, to what extent can we still treat the State institution, in its traditional configuration, against the combination of rights to culture and the ecologically balanced environment in the context of traditional knowledge? In order to respond to the research problem, the deductive

\footnotetext{
* Doutoranda em Direito pela Universidade do Rio dos Sinos (UNISINOS). Professora e Coordenadora de Pesquisa, Monografia e Extensão da Faculdade de Direito de Santa Maria (FADISMA). Mestre em Direito pelo Programa de Pós-graduação em Direito da Universidade Federal de Santa Maria (UFSM). Pesquisadora do Grupo de Pesquisa em Propriedade Intelectual na Contemporaneidade. Graduada em Direito pela UFSM. E-mail: nkuczura@gmail.com.

** Professora Adjunta do Departamento de Direito da Universidade Federal de Santa Maria (UFSM). Doutora em Desenvolvimento Regional pela Universidade de Santa Cruz do Sul (UNISC). Mestre em Integração Latino-Americana pela Universidade Federal de Santa Maria (UFSM). Graduada em Direito pela Universidade Federal de Santa Maria (UFSM). Coordenadora do Grupo de Pesquisa em Propriedade Intelectual na Contemporaneidade, certificado pela UFSM e registrado no CNPQ E-mail: isabelcsdg@gmail.com.
} 
method and the structuralist procedure were used as method of approach and procedure respectively.

Keywords: Traditional knowledge associated with biodiversity; State; People; Sovereignty; Territory.

\section{INTRODUÇÃO}

O Estado, desde a sua origem, apresenta como elementos configuradores a soberania, o território e o povo. A soberania permite ao Estado que este não seja submisso, possua independência, bem como lhe atribui o poder de se organizar juridicamente dentro de uma base física. O território, dessa forma, delimita o espaço geográfico em que se exerce a soberania. Por fim, o povo é tido como o conjunto de pessoas que se reúnem por intermédio de uma identidade forjada.

Ocorre que desde o seu surgimento, diversas novas situações emergiram, merecendo destaque aquelas impulsionadas pela globalização. Nesse cenário, pode-se, apenas a título exemplificativo, citar as questões atinentes ao terrorismo, às novas tecnologias de controle, às novas tecnologias de transformação, ao meio ambiente etc. Nesse cenário, de temas emergentes, encontram-se os denominados conhecimentos tradicionais associados à biodiversidade, que se configuram como sendo conhecimentos desenvolvidos pelas comunidades tradicionais, que em razão de seu valor de mercado, atraem a atenção dos bioprospectores. Trata-se, pois, de uma situação que abarca o direito humano à cultura e o direito humano ao meio ambiente ecologicamente equilibrado de forma conjunta.

Assim, a partir dessa situação concreta, cabe perquirir em que medida pode-se, ainda, tratar da instituição Estado, tendo como base a sua configuração tradicional, frente à conjugação dos direitos à cultura e ao meio ambiente ecologicamente equilibrado no âmbito dos conhecimentos tradicionais associados à biodiversidade? A partir desse questionamento, buscase verificar, se os elementos caracterizadores do Estado na sua acepção tradicional, ainda, imperam na atual conjuntura que impera diante da globalização.

Para responder ao problema de pesquisa posto, adotou-se como método de abordagem o dedutivo, uma vez que se realiza uma análise decrescente no sentido de que primeiramente se observam os institutos de forma separada, para posteriormente realizar a ligação entre os mesmos. Em outras palavras, em um primeiro momento se aprecia a questão atinente à 
conceituação tradicional de Estado e à composição dos conhecimentos tradicionais associados, para, ao final, auferir como se opera a relação entre ambos.

Já como método de procedimento empregou-se o estruturalista, pois se parte da análise de fenômenos concretos, quais sejam o Estado e os conhecimentos tradicionais associados à biodiversidade, para se elevar a um nível abstrato, a fim de verificar a viabilidade de se tratar de Estado em sua concepção clássica frente aos conhecimentos tradicionais. A partir disso, ao final, se retorna ao caso concreto, para auferir a viabilidade de aplicação do que foi estruturado abstratamente. Já como teoria de base utilizaram-se os ensinamentos do professor Jose Luis Bolzan de Morais no que tange à teoria do Estado e da professora Juliana Santilli em relação aos conhecimentos tradicionais associados.

Ademais, para uma melhor compreensão do tema, o presente artigo foi dividido em três capítulos. No primeiro capítulo, analisar-se-ão os três elementos caracterizadores do Estado em sua acepção clássica. No segundo capítulo, demonstrar-se-á a interrelação dos direitos humanos à cultura e ao meio ambiente ecologicamente equilibrado no âmbito dos denominados conhecimentos tradicionais associados. Por fim, no terceiro e último capítulo, verificar-se-á em que medida, ainda, é possível tratar da figura do Estado tendo em vista às problemáticas emergentes com a globalização, mais especificamente aquela atinente aos conhecimentos tradicionais associados à biodiversidade.

\section{TERRITÓRIO, POVO E SOBERANIA ENQUANTO ELEMENTOS CARACTERIZADORES TRADICIONAIS DO "ESTADO"}

A instituição estatal (Estado Moderno), que é o mecanismo político institucionalizador do poder (MENEZES NETO, 2016, p. 29), desde a sua origem, está formado estruturalmente por três elementos basilares, quais sejam: soberania, território e povo. Tais, características conferiam à nova forma estatal contornos políticos-jurídicos-administrativos e lhe fundaram enquanto ambiente espaço-temporal de uma época nova. (MORAIS, 2015, p. 865) É importante, nesse viés, ressaltar que o Estado diferencia-se, primordialmente, “[...] das demais coletividades humanas porque ele é uma coletividade soberana pelo fato de dispor do monopólio da força armada organizada sobre o seu território.” (SILVA, 2015, p. 15) 
Nesse cenário, é importante vislumbrar que embora as três características estejam presentes quando se trata de Estado, a soberania é aquela me merece maior relevo. Isso porque tradicionalmente prevalece "o modelo do Estado-nação juridicamente e politicamente construído com base na idéia de soberania.” (FERREIRA FILHO, 2000, p. 84) Tanto é assim, que, por exemplo, a Constituição Federal Brasileira coloca já no seu artigo primeiro, a soberania como sendo um dos seus fundamentos. (BRASIL, 1988)

No que tange ao surgimento do conceito de soberania não existe um marco teórico preciso e uníssono. Contudo, sabe-se que "o conceito de soberania pode ser encontrado no esforço de concentração do poder político levado a cabo por determinados reis e príncipes ao longo do processo de superação da poligarquia medieval.” (LEWANDOWSKI, 2004, p. 201) Já como característica fundamental do Estado, passa a ser tratada, teoricamente, pela primeira vez por Jean Bordin, em 1567, na obra denominada Les Six Livres de la République. (MORAIS, 2001, p. 26) Dessa forma, em que pese o termo soberania não tenha sido uma criação do século XVI, foi a partir desse momento que se determinou a sua acepção como é tida nos dias atuais. (MAGALHÃES, 2015, p. 30)

Nesse viés, a soberania é tida como um poder que não admite outro superior a ele. Aludida ausência de reconhecimento se opera tanto no plano interestatal quanto no plano interno. (FERREIRA FILHO, 2000, p. 85) A soberania, no plano externo, importa na exclusão de subordinação, de dependência em relação a outros Estados ou Organismos estrangeiros. Já no plano interno, implica na prevalência sobre o seu território e no domínio em relação aos cidadãos que nele residem. (BETTATI, 1995, p. 44) Dessa forma, é possível verificar que a soberania

[...] caracteriza-se, historicamente, como um poder que é juridicamente incontrastável, pelo qual se tem a capacidade de definir e decidir acerca do conteúdo e da aplicação das normas, impondo-as coercitivamente dentro de um determinado espaço geográfico, bem como fazer frente a eventuais injunções externas. Ela é, assim, tradicionalmente tida como una, indivisível, inalienável e imprescritível. (MORAIS, 2011, p. 28)

Diante disso, vislumbra-se que o elemento da soberania confere ao Estado a insubmissão, a independência, bem como o poder de se organizar juridicamente. Ou seja, o Estado não precisa se submeter a determinações advindas de outros Estados ou Organizações, assim como determina a forma como se regerão os cidadãos e demais instituições no interior 
de seu território. Assim, quando se fala em soberania não há a prevalência da vontade do mais forte em relação ao mais fraco.(OLIVEIRA, 2002, p. 72)

Frise-se, nesse norte, que a teoria da soberania exige que cada Estado respeite, também a soberania dos demais. Sendo assim, “[...] nenhum Estado tem o direito de alargar as suas competências por decisão unilateral, sob pena de atentar contra a soberania do outro." .(OLIVEIRA, 2002, p. 75) Ou seja, há um limite ao exercício da soberania de cada Estado. Isso porque quando o Estado ultrapassa essa limitação acaba impondo os seus anseios e interesses em relação ao outro que deixa de exercer a sua soberania.

Ao lado da soberania, o território, também, revela-se como sendo um elemento basilar do Estado, que, assim, como aquele, emergiu após 1500. (RANIERI, 2013, p. 115) Na realidade, o território complementa o conceito de soberania, posto que se revela como sendo o espaço geográfico em que aquela é exercida. (MORAIS, 2015, p. 865) Assim, o território pode ser conceituado como sendo a base física do Estado, que abarca "a área terrestre, as águas internas (fluviais, lagoas e lagos), os espaços adjacentes à costa marítima (mar territorial de 200 milhas náuticas, e ilhas), o espaço aéreo sobrejacente ao território terrestre e marítimo." (RANIERI, 2013, p. 115) O território, nada mais é, portanto, do que um espaço geográfico delimitado por fronteiras. (MORAIS, 2011, p. 27)

Diante da sua conceituação, verifica-se que o território é um importante elemento do Estado, posto que tem como função fixar fronteiras, bem como delimitar o âmbito de validade jurídica das normas. (RANIERI, 2013, p. 116) Diante dessas funções, pode-se verificar que

\begin{abstract}
O território desempenha uma função positiva de que tudo e todos que se encontram nos seus limites ficam sujeitos à sua autoridade e uma função negativa de exclusão de toda e qualquer outra autoridade diversa daquela do Estado, sendo regido pelo princípio da efetividade, limitando-se ao espaço físico sobre o qual o Estado efetivamente exerce o seu poder soberano. (STRECK; MORAIS, 2014)
\end{abstract}

Ainda, conjuntamente com os dois elementos acima trazidos, encontra-se o povo, que é o elemento pessoal. Esse se liga à questão do território, no sentido que é “"[...] um conjunto de pessoas que se vinculam artificialmente por intermédio de uma identidade forjada por características definidas aleatoriamente [...]” (MORAIS, 2015, p. 865) Em outras palavras, o povo constituísse pelos indivíduos que se encontram vinculados ao Estado por meio da nacionalidade e da cidadania (RANIERI, 2013, p. 108)

Evidente, portanto, que não se pode confundir o povo, enquanto elemento caracterizador do Estado, com a denominada população, posto que esta 
diz respeito a todos os que habitam o território, ou seja, engloba todas as pessoas, mesmo que temporariamente permaneçam em um território, sem nada dizer a respeito dos vínculos com o Estado, pois se apresenta como um conceito demográfico-matemático, e povo, que realça o aspecto jurídico do grupo vincula do a uma determinada ordem normativa, mostrando-se como um conceito jurídico-constitucional. (STRECK; MORAIS, 2014)

A população, portanto, não é um elemento caracterizador do Estado, uma vez que fazer parte de uma determinada população apenas demonstra que aquele indivíduo habita aquele território, não trazendo, contudo, nenhuma vinculação com aquele Estado. Diferentemente, o povo, que é elemento da instituição em análise, refere-se ao vínculo daquele determinado indivíduo com uma ordem normativa.

Esses três são, portanto, os elementos caracterizadores do Estado na sua acepção tradicional, ou seja, características que emergiram com a concepção de Estado. Ocorre que, "no transcurso de sua história, o Estado, erigido como tal no bojo da modernidade, viu-se envolto em um largo processo de consolidação e transformações" (MORAIS, 2011, p. 18). Em razão disso, passou-se a perquirir se era necessário tratar do fim do Estado, de sua transformação, seu recomeço ou sua continuidade. (MORAIS, 2011, p. 18).

Nesse contexto, para verificar qual é a atual roupagem do Estado - se é que ainda se pode falar em Estado - passa-se a analisar especificamente a temática referente à conjugação de direitos humanos de segunda e terceira dimensão no que se refere ao caso específico dos conhecimentos tradicionais associados à biodiversidade. Frise-se que, embora seja apenas um recorte, posto que a situação atual do Estado pode ser vista sob diversas outras situações específicas, a análise que ora se pretende reflete a realidade e a posição do Estado frente às modificações que emergiram no mundo nas últimas décadas, mormente tendo em vista o fenômeno da globalização. ${ }^{\dagger}$

\section{A EMERGÊNCIA DA CONJUGAÇÃO DE DIREITOS HUMANOS DE SEGUNDA E TERCEIRA DIMENSÃO: UMA ANÁLISE SOB O PRISMA DOS CONHECIMENTOS TRADICIONAIS ASSOCIADOS À BIODIVERSIDADE}

\footnotetext{
† A globalização poder ser considerada como sendo "[...] o processo social - fortemente influenciado pelo desenvolvimento tecnológico, pela crescente velocidade dos transportes e pela "revolução informática" que deu vida a uma verdadeira e própria rede mundial de conexões espaciais e de interdependências funcionais. Esta "rede" coloca em contato entre si um número crescente de atores sociais e de eventos econômicos, políticos, culturais e comunicacionais, outrora desconectados em virtude das distâncias geográficas ou de barreiras cognitivas e sociais de vários tipos.” (ZOLO, 2010. p. 15-16).
} 
Nas últimas décadas, o mundo vem passando por inúmeras transformações, nas mais variadas searas, o que se mostra como sendo um influxo natural do fenômeno da globalização. Nesse contexto, desde meados dos anos 80, não mais impera a visão tradicional de proteção ambiental, visto que se consolidou o sociambientalismo (SANTILLI, 2005, p. 29). A partir desse novo marco, é necessário conjugar a biodiversidade* e o meio ambiente ecologicamente equilibrado com a cultura. (BIFANI, 1995, p. 156) Superou-se, portanto, a visão individualista que imperava até então.

Esse novo paradigma refletiu diretamente na elaboração da Constituição Federal de 1988, que tratou da proteção ao meio ambiente e reconheceu o direito à cultura. Direitos estes que se afastam da ideia individualista e que devem ser analisados partindo do pressuposto de que formam uma unidade dialética. (DERANI, 2008, p. 49) Dessa forma, garante-se como direitos humanos ${ }^{\S}$, ao mesmo tempo, a todos o meio ambiente ecologicamente equilibrado, sendo dever do Estado e da coletividade conservá-lo para as presentes e futuras gerações, bem como tutela-se o respeito a todas as formas de cultura, devendo as mesmas serem preservadas, como forma de respeito às diferenças.

Nesse viés, cumpre referir que os direitos à cultura e ao meio ambiente são direitos humanos, respectivamente, de segunda e terceira dimensões, posto que o primeiro se desenvolve atrelado ao Estado Social, resguardando-se o direito ao acesso às fontes de cultura nacional, a liberdade de expressão e de manifestações culturais, o direito de criação cultural e o direito à identidade cultural. Já o segundo se revela como sendo um direito de natureza transindividual, o qual se configura como um desdobramento do direito à vida no que tange a sua concepção referente à qualidade.( CUREAU; LEUZINGER, 2013, p. 64-65)

A proteção ao direito à cultura, no âmbito da Constituição Federal, se operou de forma ampla, visto que não houve qualquer delimitação de seu conteúdo. Dessa maneira, ao não elencar de forma taxativa quais são os direitos culturais protegidos, a Constituição Federal deu espaço à mobilidade das próprias identidades criadas no decorrer do tempo e do espaço,

\footnotetext{
* Deve-se ter presente que em virtude de a expressão biodiversidade ser tão grande em escopo e abstrata em natureza é difícil, inclusive para os estudiosos da área, ter uma conceituação precisa. Diante disso, na atualidade, tem-se utilizado comumente o conceito apresentado pela Convenção sobre Diversidade Biológica, referindo-se, diante disso, o vocábulo biodiversidade "à qualidade, escala e extensão de diferenças entre as entidades biológicas num dado conjunto.” Representa, assim, toda a vida em si mesma. (INOUE, 2007).

$\S$ Direitos Humanos podem ser tidos como “[...] conjunto de valores históricos, básicos e fundamentais que dizem respeito à vida digna jurídico-político-psíquico-econômica-física e afetiva dos seres e de seu habitat, tanto daqueles do presente quanto daqueles do por vir." (MORAIS, 2011. p. 88).
} 
reconhecendo que estas são celebrações móveis. (HALL, 2006, p. 13) A cultura, portanto, deve ser tida como um sistema simbólico, que é dinâmico, alterando-se de acordo com o tempo, o espaço e a sociedade em que se insere. (LITAIFF, 1996, p. 20) Néstor Garcia Canclini (2009, p. 41), igualmente, reconhece o caráter cambiente e processual do que denomina de cultural. Assim, determina que "a cultura abarca o conjunto dos processos sociais de produção, circulação e consumo da significação na vida social."

Em que pese as divergências existentes quanto à conceituação de cultura, pode-se afirmar que a mesma denota

\footnotetext{
um padrão de significados transmitido historicamente, incorporado em símbolos, um sistema de concepções herdadas expressas em forma simbólicas por meio das quais os homens comunicam, perpetuam e desenvolvem seus conhecimentos e suas atividades em relação à vida. (GEERTZ, 1989, p. 66)
}

Verifica-se, assim, que o reconhecimento ao direito cultural implica, por conseguinte, ao respeito à diferença e à interculturalidade, ao lado do princípio da igualdade. A aludida interculturalidade deve ser compreendida como um meio que permite a coexistência de culturas, que se mostram como sendo diferentes, uma vez que assegura o reconhecimento do direito à diferença sem impor práticas políticas assimilacionistas e de segregação, bem como sem promover a perda dos elementos constituidores de cada cultura.(LUCAS, 2010, p. 253)

Além do direito à cultura, a Constituição Federal prevê a necessária proteção ao meio ambiente ecologicamente equilibrado. Referida tutela encontra-se primordialmente elencada no artigo 225, que é uma síntese de todos os dispositivos constitucionais que versam acerca do meio ambiente e estão enxertos na Constituição.(BENJAMIN, 2011, p. 124)

O artigo 225 da Constituição Federal, em seu caput, dispõe que "Todos têm direito ao meio ambiente ecologicamente equilibrado, bem de uso comum do povo e essencial à sadia qualidade de vida, impondo-se ao Poder Público e à coletividade o dever de defendê-lo e preservá-lo para as presentes e as futuras gerações." (BRASIL, 1988) Carreia-se, pois, o conceito de desenvolvimento sustentável, que foi estampado, pela primeira vez, no Relatório da Comissão Mundial sobre Meio Ambiente e Desenvolvimento.(ORGANIZAÇÃO DAS NAÇÕES UNIDAS, 1987) Há, pois, uma preocupação intergeracional quando se trata do direito difuso em questão. Isso ocorre porque diz respeito "a uma série indeterminada ou de difícil determinação de sujeitos, de lugares e de gerações distintas” (MORAIS, 2008, p. 70) Ao lado disso, é importante ter presente que o meio ambiente possui uma dimensão global, ou seja, 
os impactos de devastação nessa seara vão além das fronteiras do local em que se operou a ação ou a omissão.(MORAIS, 2008, p. 70-73)

Assim, frente à conceituação de referidos direitos, resta latente, conforme já referido anteriormente, que o meio ambiente e a cultura não podem ser analisados como sendo partes, ou seja, isoladamente, mas sim de forma conjunta, visto que "a cultura deve ser compreendida como gradual continuação da natureza" (DERANI, 2008, p. 50). Ou seja, "não obstante, do que se trata realmente é de aceitar que ao discurso da biodiversidade corresponde também uma diversidade cultural, dada a existência de grupos humanos que adaptaram e enriqueceram a natureza.” (ALONSON, 2005, p. 293) Em outras palavras, verifica-se que a questão ambiental passa a se agregar à questão social. .(MORAIS, 2008, p. 71)

É nesse contexto de necessária imbricação entre o direito à cultura e o meio ambiente ecologicamente equilibrado que se inserem os conhecimentos tradicionais associados à biodiversidade, os quais se configuram como sendo um conjunto complexo de informações intergeracionais perpetuado pelas comunidades locais.(SANTILLI, 2005, p. 192) Em suma, as comunidades locais, dentre as quais se podem citar os índios, quilombolas e ribeirinhos, desenvolvem determinados conhecimentos, que passam a integrar a sua cultura, ou seja, a forma como os mesmos vêem e se relacionam com o mundo.

Aludidos conhecimentos estão atrelados ao ambiente em que as comunidades encontram-se inseridas. Isso ocorre porque o desenvolvimento daqueles se revela viável em razão deste. Da mesma forma, a proteção do meio ambiente se opera, em grande parte, em virtude dos conhecimentos empregados naquela determinada localidade. Esses conhecimentos tradicionais são, pois, conjuntos complexos de informações intergeracionais, que não se restringe a um simples repertório de ervas medicinais, abarcam, dessa forma,

\footnotetext{
desde técnicas de manejo de recursos naturais até métodos de caça e pesa, conhecimentos sobre diversos ecossistemas e sobre propriedade farmacêuticas, alimentícias e agrícolas de espécies as próprias categorizações e classificações de espécies de flora e fauna utilizadas pelas populações tradicionais. .(SANTILLI, 2005, p. 192)
}

Verifica-se, pois, que em virtude de suas particularidades, as comunidades tradicionais possuem uma imbricada relação com a natureza. A própria cultura dessas comunidades se desenvolve levando em consideração o ambiente em que estão alocadas. Dessa forma, em razão dessa ligação, as comunidades tradicionais têm-se mostrado fundamentais na preservação do meio ambiente equilibrado. Verifica-se, portanto, que é imperioso "aceitar que ao discurso da 
biodiversidade corresponde também uma diversidade cultural, dada a existência de grupos humanos que adaptaram e enriqueceram a natureza." (ALONSO, 2005, p. 293)

Em que pese a importância dos conhecimentos tradicionais para a preservação do meio ambiente ecologicamente equilibrado e da cultura, o certo é que muitos deles, em razão do seu possível valor econômico, passaram a atrair a atenção de grandes empresas detentoras de tecnologia. Empresas estas que são denominadas de bioprospectoras, posto que realizam a coleta de material biológico e efetuam acesso aos recurso genéticos das comunidades em busca de novos compostos bioquímicos, que tenham princípios ativos que possam ser manejados na produção de novos produtos farmacêuticos, químicos e alimentares, por exemplo. .(SANTILLI, 2017) Nesse aspecto, tem-se que os conhecimentos tradicionais alojam-se nos países do Sul e as tecnologias encontram nos países do Note.

Assim, ao mesmo tempo, em que se tem o interesse coletivo das comunidades tradicionais em relação aos seus conhecimentos, no sentido de perpetua-los para as futuras gerações, protegendo o ambiente em que se encontram inseridas, tem-se o interesse dos bioprospectores de auferir vantagens econômicas por meio da apropriação desses recursos. Apropriação essa que está pautada na ótica da propriedade.

Nesse norte, embora existam outras legislações regulamentando a matéria, impera no que tange aos conhecimentos tradicionais o determinado no Acordo sobre os Aspectos dos Direitos de Propriedade Intelectual Relacionados ao Comércio (TRIPS). Referido Acordo permite a concessão de patentes em relação aos conhecimentos tradicionais associados à biodiversidade. Prevalece, pois, a ótica mercadológica internacional, ou seja, a legislação aplicável é regida pela busca desenfreada pelo lucro, prevalecendo o interesse dos bioprospectores, os quais não se preocupam com o meio ambiente e tampouco com a cultura. Isso ocorre porque a economia ou o chamado meio de produção moderno não observam que os recursos naturais são finitos e esgotáveis, apenas os utilizam sem observância do binômio tempo-espaço, pautados na justificativa da necessidade de contínuo crescimento.(DERANI, 2008, p. 101)

Vislumbra-se, pois, que em razão da globalização e da distribuição de poder de forma diversa entre os países do Norte e do Sul, aqueles acabam dominando o cenário mundial, fazendo com que os seus interesses influenciem outras culturas e países. Assim, frente a esse cenário, em que prevalece o interesse dos bioprospectores, não se atentando, pois, às questões referentes ao meio ambiente ecologicamente equilibrado e à cultura, bem como aos impactos 
que essa falta de proteção efetiva pode causar, cabe perquirir se, ainda, é possível reconhecer o "Estado" em sua acepção tradicional? Em outras palavras, ainda, é possível falar do Estado composto estruturalmente pelas características da soberania, território e povo?

\section{A (IN) COMPATIBILIDADE DA TRADICIONAL ACEPÇÃO DE "ESTADO" FRENTE AO CASO DOS CONHECIMENTOS TRADICIONAIS ASSOCIADOS À BIODIVERSIDADE}

A partir da análise da situação atual dos conhecimentos tradicionais associados à biodiversidade, bem como dos direitos humanos ${ }^{* *}$ que são a sua base, é possível verificar que não é mais possível tratar de dois elementos do Estado na sua tradicional conceituação, quais sejam: soberania e território. Verifica-se, nesse ponto, o que Jose Luis Bolzan de Morais (2011) denominou de crise conceitual do Estado.

Quanto à soberania, tradicionalmente, a mesma implicava no fato de o Estado ser o centro único e autônomo de poder e o protagonista no seu território.(MORAIS, 2011, p. 28) Quando se tratou de conhecimentos tradicionais, contudo, verifica-se que tal não mais prevalece, posto que se verifica claramente a ingerência de um Estado em outro; a necessidade de união entre Estados com interesses similares, para fazer frente àqueles que utilizam do seu poderio como forma de proceder à ingerência; bem como a forte influência das empresas multinacionais.

Quanto à ingerência de um Estado em outro, retirando deste o seu poder de livre decisão, tal resta cristalino, a partir do momento em que os países do Sul aderiram ao Acordo Trips. Isso porque ao permitir o patenteamento dos conhecimentos tradicionais associados à biodiversidade, atentou-se aos interesses exclusivos dos países do Norte. Opção essa que tão somente foi possível, uma vez que os países do Norte se utilizaram do seu poder políticoeconômico para forçar os países do Sul a aderirem a normas que melhor atendessem aos seus interesses. Apenas a título exemplificativo, tem-se que "o Brasil durante a fase de negociações

\footnotetext{
** Embora não seja o objeto primordial do presente trabalho, não se podem olvidar que os conhecimentos tradicionais associados envolvem direitos de segunda e terceira dimensão, atrelados, respectivamente, à questão da carência e do risco. Assim, o que se tem no caso em questão é a demonstração clara de que a direitos sociais foram agregados novos direitos. Ocorre que isso se opera em um cenário em que sequer a questão social foi atendida pelo Estado em todos os lugar e para todas as pessoas e, mesmo sem tal solução, o mesmo deve passar a se preocupar com uma nova questão e, além disso, com os direitos acima mencionados de forma interligada. Sobre o tema ver: (MORAIS, 2008).
} 
do ADPIC, viveu sob ameaça constante de 'retaliações' comerciais por parte dos Estados Unidos, inclusive sofrendo sanções materializadas em medidas restritivas às importações de seus produtos [...].” (PIMENTEL, 2006, p. 299)

Não bastasse o não respeito à soberania pelos próprios entes estatais, ainda, há influência das transnacionais. Assim, pautando-se no capitalismo financeiro e, mais especificamente, no lucro que os conhecimentos tradicionais associados à biodiversidade podem conferir às empresas detentoras de tecnologia, as decisões dos Estados restam condicionadas aos interesses daquelas.

Nesse sentido, é o posicionamento de Ost (1995, p. 91), que referiu que é “[...] certo que a finalidade da legislação sobre as patentes é a proteção dos interesses financeiros dos investidores em matéria de pesquisa, qualquer outra consideração parece dever ceder o passo diante desse objetivo". Ainda, no mesmo sentido, revela-se a manifestação de Manoel Cunha, representante do Conselho Nacional das Populações Extrativistas em relação à nova Lei de Biodiversidade aprovada em 2015: "Comemos mosca, fomos mais lentos do que as empresas. As empresas foram para dentro, colocaram todas as suas ideias e sua força política, e o governo conduziu (o processo) à luz delas." (ASSOCIAÇÃO MINEIRA DE DEFESA DO AMBIENTE, 2017) Frise-se que esta última se trata de uma simples manifestação que bem retrata a realidade e que além de influenciar diretamente no conceito tradicional de soberania apresenta um grave problema no sentido de que "não há muito mais 'a quem se queixar', pois o poder político vêse submetido e/ou condicionado por agente econômicos, que, ao contrário dos agentes políticos, não possuem visibilidade pública [...]” (MORAIS, 2011, p. 31)

Ao lado disso, considerando a primeira situação ora retratada, que versa sobre a imposição de posturas aos países do Sul, embora ainda não implementada, já surgiu a discussão acerca da criação de formas de espaços regionais para tratar sobre a questão dos conhecimentos tradicionais, assim como outras questões.

Em suma, os Estados nacionais deixam de ser atores exclusivos e privilegiados, como foi dito antes, para se converterem num marco político e administrativo - entre tantos outros - nas negociações eco- nômicas e financeiras. Com sua soberania diluída num crescente e acelerado fluxo de interdependências, eles se tornam dependentes de saberes especializados, de recursos financeiros e de decisões políticas compartilhadas. Incapazes de configurar um "espaço interior" coerente, por um lado, e demasiadamente lentos com relação à velocidade das transações globais, por outro, seu poder real somente lhes permite adequar-se a um quadro complexo - quadro esse que em muito o transcende. (FARIA, 2011, p. 71) 
Não bastasse isso, quando se está tratando sobre a questão ambiental, um dos direitos que compõe os conhecimentos tradicionais associados, deve-se considerar o risco que lhe ínsito. Assim, passa-se de um panorama da carência para o risco. (MORAIS, 2008, p. 66) Risco este que não se limita a um determinado espaço territorial, ao revés, os impactos dos dilemas ambientais repercutem nas mais variadas esferas e espaços, não sendo possível precisar, por vezes, sequer o alcance de um determinado dano.

Apenas a título exemplificativo, o consumo excessivo de determinados bens no hemisfério Norte, implicará em consequências danosas também para o Hemisfério Sul, e, mais do que isso, tornará a impossível o acesso de todos à uma vida equiparável.(OST, 1995, p. 394) Em outras palavras, não é possível restringir os dilemas ambientais a determinados espaços territoriais. Isso foi o que ocorreu com o caso dos milhos starlink. Esta espécie de milho transgeneticamente modificado, era destinado apenas para o consumo de animais. Porém, o seu polén foi transportado pelo vento para os campos ao redor da sua plantação e misturou-se, em grande parte, à oferta de milho destinado a consumo humano. Ainda, utilizando o exemplo dos milhos, mas demonstrando a inexistência de respeito de fronteiras estatais, tem-se o caso do México e dos Estados Unidos, uma vez que aquele não planta sementes transgênicas, mas possui milhos de tal espécie, posto que a natureza se encarrega de fazer essa transposição transfronteiriça. (PORTO-GONÇALVES, 2006)

Com a apropriação dos conhecimentos tradicionais, não será diferente, pois haverá a redução da biodiversidade dos Estados biodiversos, o que acabará acarretando impacto em todo o ambiente global. Assim, os danos ao meio ambiente e à cultura não se restringirão ao território, em que se operará a exploração dos conhecimentos em questão.

A questão ambiental, dessa forma, não se submete aos limites territoriais da ordem jurídica moderna e a suas estratégias, provocando a incapacidade de ser tratada adequadamente em um ambiente jurídico que não se abra para a ultrapassagem de tais restrições. (MORAIS, 2008, p. 73)

Assim, no que tange aos conhecimentos tradicionais associados à biodiversidade, vislumbra-se que não mais é possível falar em soberania na sua acepção clássica e sequer em limites físicos para o exercício desta. Ou seja, a soberania e o território não podem ser mais estudados como na sua tradicional concepção. Verificando-se, pois, a insuficiência do conceito tradicional de Estado na atual conjuntura, uma vez que o mesmo não é mais soberano na acepção tradicional do vocábulo e tampouco possui um território geograficamente delineado, cabe questionar como solucionar a questão da proteção dos conhecimentos tradicionais e, por 
conseguinte, da cultura e do meio ambiente ecologicamente equilibrado se não por meio da instituição Estado na sua acepção tradicional?

Quanto à própria problemática acerca da manutenção da figura do Estado, existem diversos posicionamentos, os quais se coadunam com a análise da problemática ora proposta. Por exemplo, "Para alguns estudiosos entusiastas, a globalização colocaria a soberania no museu da história. Outros, no entanto, afirmam que o sistema mundial de direitos contribui para o fortalecimento dos Estados.” (OLIVEIRA, 2002, p. 35)

Aqueles defensores da primeira corrente entendem que a globalização colocou em crise a soberania, uma vez que os países do Sul têm sua soberania limitada pelos ditames da economia global. Nesse viés, é a lição de Stephen Krasner, o qual refere que diante da inexistência de instituições com ascendência sobre os Estados, e frente à assimetria de poder que se verifica no campo internacional, a coerção e a imposição são meios empregados pelos mais fortes em detrimento daqueles que se revelam mais frágeis econômica e politicamente. (KRASNER, 1999)

Nesse viés, há quem defenda, que embora esteja superada a figura do Estado-Nação na sua acepção clássica, este não desaparecerá, mas sim irá se associar, formando uma nova figura, que poderia ser denominada de Comunidade. Nesta, seriam conjugados elementos da confederação com outros atinentes ao Estado Federal.(FERREIRA FILHO, 2000, p. 86-87)

Já os adeptos da segunda corrente defendem que a globalização apresenta novos desafios, os quais são campo para o fortalecimento e reavivamento dos Estados-Nação, que são quem decide em última instância, visto que possuem o monopólio das normas.

O melhor, entretanto, parece não ser adotar qualquer uma de referidas correntes, que são extremistas, mas sim relativizar a força relacionada ao Estado, em razão do esvaziamento da sua acepção tradicional, por meio da construção de espaços, que, de fato, contemplem os direitos humanos (MORAIS, 2015, p. 863), dentre os quais se alocam o direito ao meio ambiente ecologicamente equilibrado e à cultura. Assim, entende-se que o mais adequado frente à fragilidade da conceituação tradicional de Estado-Nação e da incapacidade de o mesmo proteger os direitos humanos, que dizem respeito aos conhecimentos tradicionais associados, seria pensar em um Estado Constitucional Comum-Mundial. (MORAIS, 2015, p. 864)

Assim, o que se vislumbra é que não há uma necessária ligação entre o enfraquecimento do território e da soberania enquanto elementos caracterizadores do Estado e o esvaziamento completo deste. Deve-se, portanto, repensar a questão do território, mostrando-se que este não 
é estanque e delineado - transfronterização -, como proposto originariamente, bem como refundar o conceito de soberania, no sentido de que houve a proliferação de loci em que é exercida.(MENEZES NETO, 2016)

\section{CONCLUSÃO}

Tradicionalmente, o Estado possui três características que lhe são ínsitas e conferem a sua caracterização enquanto tal. Tratam-se da soberania, do território e do povo. A primeira configura-se como sendo um poder que é juridicamente incontrastável no sentido de que o ente estatal possui capacidade para determinar a sua normativa interna, bem como repelir eventuais ingerências externas. Dessa forma, o Estado possui o poder de gerenciar as determinações dentro de uma certa base geográfica, não se falando em prevalência dos interesses dos mais fortes economicamente e tecnologicamente em relação aos mais fracos. Esse exercício de poder, portanto, opera-se limitadamente em um espaço geográfico definido, o que se denomina território e que estabelece as chamadas fronteiras. Por fim, tem-se o povo que se constitui pelos indivíduos que se encontram vinculados ao Estado por meio da nacionalidade e da cidadania.

Ocorre que essa acepção clássica de Estado, pautada nas três características acima delineadas - soberania, território e povo - não se revela mais suficiente para representar a sua atuação no âmbito atual, o que se vislumbra quando se está diante dos conhecimentos tradicionais associados à biodiversidade. Estes conhecimentos são aqueles transmitidos de geração em geração e relacionam os direitos humanos à cultura e ao meio ambiente ecologicamente equilibrado. Há, pois, em seu âmbito a conjugação da questão social e da questão ambiental. Assim, vislumbra-se que o Estado mesmo sem ter conseguido solucionar a primeira, depara-se com uma nova questão: a do risco e, mais do que isso, com os problemas relativos à carência e ao risco de forma associada.

Além dessa insuficiência, tem-se a impossibilidade de tratamento da questão de território e de soberania como conhecidos na sua conceituação clássica. Isso porque as fronteiras, mormente se tratando do meio ambiente, tornaram-se mais flexíveis, surgindo uma nova ideia de transfronteirização. Ao lado disso, verifica-se que o Estado já não mais possui o poder juridicamente incontrastável, sendo insubmisso, independente e tendo a capacidade de se organizar juridicamente. Em outras palavras, já não se mostra mais possível tratar da soberania 
na sua concepção clássica. Tal verifica-se em diversas situações que envolvem os conhecimentos tradicionais.

Inicialmente, vislumbra-se quando se está diante dos conhecimentos tradicionais associados há uma forte ingerência dos países do Norte em relação aos países do Sul. Ou seja, há uma sobreposição de poderes, que constrangem estes, mesmo sem o seu interesse, a aderirem a determinadas posturas, condutas e normas. Não bastasse a interferência de alguns Estados em outros, verifica-se a forte influência de transnacionais no que tange à fixação da regulamentação aplicável aos conhecimentos tradicionais associados à biodiversidade. Nesse sentido, materializando essas duas situações, passou-se a permitir com a vigência do Acordo Trips, o patenteamento dos conhecimentos tradicionais associados. Dessa maneira, além de romper com o conceito tradicional de soberania, tal implica no desrespeito aos direitos humanos ao meio ambiente ecologicamente equilibrado e à cultura.

Assim, restando latente à insuficiência do conceito tradicional de Estado para solucionar a problemática envolvendo os conhecimentos tradicionais associados à biodiversidade, passouse a questionar qual seria o caminho. Nesse viés, a teoria do Estado aponta para diversas soluções, parecendo, no entanto a mais viável entender que houve sim um enfraquecimento dos conceitos de soberania e território, porém que o Estado não se esvaziou por completo, ou seja, não se deve adotar nenhuma corrente extremista no sentido de seu total esquecimento ou completo fortalecimento. Nesse norte, o mais acertado para proteger, efetivamente, os conhecimentos tradicionais associados à biodiversidade seria pensar em um Estado Constitucional Comum-Mundial.

\title{
REFERÊNCIAS
}

ALONSO, Margarita Flórez. Proteção do Conhecimento Tradicional? SANTOS, Boaventura de Sousa (org.). Semear outras soluções: os caminhos da biodiversidade e dos conhecimentos rivais. Rio de Janeiro; Civilização Brasileira, 2005.

\author{
ASSOCIAÇÃO MINEIRA DE DEFESA DO AMBIENTE. Presidente sanciona lei \\ sobre acesso à biodiversidade. Disponível em: < \\ http://www.amda.org.br/?string=interna-noticia\&cod=7302>. Acesso em: 20 jul. 2017.
}


BENJAMIN, Antônio Herman. Direito Constitucional Ambiental Brasileiro. In: CANOTILHO, José Joaquim Gomes; LEITE, José Rubens Morato. Direito

Constitucional Ambiental Brasileiro. 4. ed. São Paulo: Saraiva, 2011.

BETTATI, Mario. O direito de ingerência: mutação da ordem internacional. Lisboa: Instituto Piaget, 1995.

BIFANI, Paolo. Medio ambiente y dessarrollo sostenible. 4. ed. rev. Madrid: Instituto de Estudios Políticos para América Latina y Africa (EPALA), 1999.

BRASIL. Constituição Federal. Brasília: Senado Federal, 1988. Disponível em: <http://www.planalto.gov.br/ccivil_03/Constituicao/Constituiçao.htm>. Acesso em: 06 jul. 2017.

CANCLINI, Néstor García. Diferentes, Desiguais e Desconectados. 3. ed. Rio de Janeiro: UFRJ, 2009.

CUREAU, Sandra; LEUZINGER, Marcia Dieguez. Direito Ambiental. Rio de Janeiro: Elsevier, 2013.

DERANI, Cristiane. Direito Ambiental Econômico. São Paulo: Saraiva, 2008.

FARIA, José Eduardo. O estado e o direito depois da crise. 1. ed. São Paulo: Saraiva, 2011.

FERREIRA FILHO, Manoel Gonçalves. O Estado do Futuro e o Futuro do Estado. In: Direito e Democracia. v. 1. n.1. 1 sem. 2000. Disponível em: < http://www.egov.ufsc.br/portal/sites/default/files/2236-6825-1-pb.pdf >. Acesso em: 20 jun. 2017. p. 81-94.

GEERTZ, Clifford. A interpenetração das culturas. Rio de Janeiro: Livros Técnicos e Científicos Editora, 1989.

HALL, STUART. A Identidade Cultural na Pós-Modernindade. 11. ed. Rio de Janeiro: DPeA, 2006. 
INOUE, Cristina Yume Aoki. Regime global da biodiversidade: o caso Mamirauá. Brasília: Universidade de Brasília, 2007.

KRASNER, Stefen D. Sovereignty: organized hipocrksy. Princeton: Princeton University Press, 1999.

LEWANDOWSKI, Enrique Ricardo. Globalização, regionalização e soberania. São Paulo: Juarez de Oliveria, 2004.

LITAIFF, Aldo. As divinas palavras: identidade étnica ds Guarani-Mbya. Florianópolis: Editora da UFSC, 1996.

LUCAS, Doglas César. Direitos Humanos e Interculturalidade: um diálogo entre a igualdade e a diferença. Ijuí: Editora Unijuí, 2010.

MAGALHÃES, Juliana N. Formação do conceito de soberania: História de um paradoxo. São Paulo: Saraiva, 2015.

MENEZES NETO, Elias Jacob de. Surveillance, democracia e direitos humanos: Os limites do Estado na Era do Big Data. 2016. 293f. Tese (Doutorado em Direito) Universidade do Vale do Rio dos Sinos, São Leopoldo, 2016.

MORAIS, José Luis Bolzan de. Do estado social das "carências" ao estado social de "riscos". Ou: de como a questão ambiental especula por uma nova "cultura" jurídicopolítica. In: STRECK, Lenio Luiz; MORAIS, José Luis Bolzan de. Constituição, Sistemas Sociais e Hermenêutica. Anuário 2007. n. 4. Porto Alegre: Livraria do Advogado, 2008.

MORAIS, Jose Luis Bolzan de; HOFFMAN, Fernando. Por uma identidade constitucional “comum”. In: Novos Estudos Jurídicos. v. 20. n. 3. 2015. Disponível em: <https://siaiap32.univali.br/seer/index.php/nej/article/view/8357/4699>. Acesso em: 22 jun. 2017. p. 860-884.

MORAIS, José Luis Bolzan. As crises do Estado e da Constituição e a transformação espaço-temporal dos direitos humanos. 3. ed. rev. ampl. Porto Alegre: Livraria do advogado, 2011. 
OLIVEIRA, Liziane Paixão Silva. Globalização e soberania: o Brasil e a biodiversidade amazônica. Brasília: Fundação Milton Campos; Conselho de Reitores das Universidades Brasileiras, 2002.

ORGANIZAÇÃO DAS NAÇÕES UNIDAS. Relatório Brundtland. Disponível em: < http://www.un.org/documents/ga/res/42/ares42-187.htm >. Acesso em: 20 jun. 2017.

OST, François. A natureza à margem da lei: a ecologia à prova do direito. Trad. Joana Chaves. Lisboa: Instituto Piaget, 1995.

PIMENTEL, Luiz Otávio. O Acordo sobre os Aspectos dos Direitos de Propriedade Intelectual Relacionados ao Comércio. In: WACHOWICZ, Marcos. Propriedade intelectual e internet: Uma perspectiva integrada à sociedade da informação. 1. ed. 5. tir. Curitiba: Juruá: 2006.

PORTO-GONÇALVES, Carlos Walter. A globalização da natureza e a natureza da globalização. Rio de Janeiro: Civilização brasileira, 2006.

RANIERI, Nina Stocco. Teoria do Estado: do Estado do Direito ao Estado Democrático do Direito. Barueri: Manole, 2013.

SANTILLI, Juliana. Conhecimentos tradicionais associados à biodiversidade: Elementos para a construção de um regime jurídico "sui generis" de proteção. In: Encontro Anual da Associação Nacional de Pós-Graduação e Pesquisa em Ambiente e Sociedade. Disponível em: < http://www.anppas.org.br/encontro_anual/encontro2/GT/GT08/juliana_santilli.pdf >. Acesso em: 22 jul. 2017.

SANTILLI, Juliana. Socioambientalismos e novos direitos: A proteção jurídica da diversidade biológica e cultural. São Paulo: Fundação Peirópolis, 2005.

SILVA, Maria Beatriz Oliveira da. A soberania (ambiental) do "lado de cá" frente ao meio ambiente como patrimônio comum da humanidade. In: SILVA, Maria Beatriz Oliveira da.; Mello, Rafaela da Cruz. Soberania e meio ambiente: a soberania ambiental vista do lado de cá. Curitiba: CRV, 2015. 
STRECK, Lenio Luiz; MORAIS, Jose Luis Bolzan de. Ciência Política e Teoria do Estado. 8. ed. Porto Algre: Livraria do Advogado, 2014.

ZOLO, Danilo. Globalização: um mapa dos problemas. Tradução: Anderson Vichinkeski Teixeira. Florianópolis: Conceito Editorial, 2010. 